\title{
Occurrence of the invasion associated marker (iam) in Campylobacter jejuni isolated from cattle
}

Yasser M Sanad ${ }^{1 \dagger}$, Issmat I Kassem ${ }^{1 \dagger}$, Zhe Liu', Jun Lin², Jeffrey T LeJeune ${ }^{1}$ and Gireesh Rajashekara ${ }^{1 *}$

\begin{abstract}
Background: The invasion associated marker (iam) has been detected in the majority of invasive Campylobacter jejuni retrieved from humans. Furthermore, the detection of iam in C. jejuni isolated from two important hosts, humans and chickens, suggested a role for this marker in C. jejuni's colonization of multiple hosts. However, no data exist regarding the occurrence of this marker in C. jejuni isolated from non-poultry food-animals such as cattle, an increasingly important source for human infections. Since little is known about the genetics associated with C. jejuni's capability for colonizing physiologically disparate hosts, we investigated the occurrence of the iam in C. jejuni isolated from cattle and assessed the potential of iam-containing cattle and human isolates for chicken colonization and human cell invasion.

Results: Simultaneous RAPD typing and iam-specific PCR analysis of 129 C. jejuni isolated from 1171 cattle fecal samples showed that $8(6.2 \%)$ of the isolates were iam-positive, while 7 (54\%) of human-associated isolates were iam-positive. The iam sequences were mostly heterogeneous and occurred in diverse genetic backgrounds. All iam-positive isolates were motile and possessed important genes (cadF, ciaB, cdtB) associated with adhesion and virulence. Although certain iam-containing isolates invaded and survived in INT-407 cells in high numbers and successfully colonized live chickens, there was no clear association between the occurrence, allelic sequence, and expression levels of the iam and the aforementioned phenotypes.

Conclusions: We show that the prevalence of iam in cattle C. jejuni is relatively lower as compared to isolates occurring in humans and chickens. In addition, iam was polymorphic and certain alleles occur in cattle isolates that were capable of colonizing and invading chickens and human intestinal cells, respectively. However, the iam did not appear to contribute to the cattle-associated C. jejuni's potential for invasion and intracellular survival in human intestinal cells as well as chicken colonization.
\end{abstract}

Keywords: Campylobacter jejuni, Cattle, Invasion, Host colonization, Invasion associated marker (iam)

\section{Background}

Campylobacter jejuni is an important foodborne pathogen that can cause a variety of infections in humans [1]. Additionally, C. jejuni colonizes important food-animals such as chicken and cattle, which together constitute an important source for human infections with this pathogen [2]. Although C. jejuni can occur in multiple hosts, it is more readily transmissible within species [3]. Once established in a new host, $C$. jejuni has a remarkable

\footnotetext{
*Correspondence: rajashekara.2@osu.edu

+ Contributed equally

${ }^{1}$ Food Animal Health Research Program, Ohio Agricultural Research and Development Center, Department of Veterinary Preventive Medicine, The Ohio State University, Wooster, OH 44691, USA

Full list of author information is available at the end of the article
}

capacity for acquiring genetic material that facilitates adaptation to the host environment [3]. Efficient host colonization can be essential in pathogenesis mechanisms, including host cell invasion and associated sequelae [4]. Furthermore, numerous studies, using live chicken models and in vitro human cell lines, have suggested multiple genetic determinates that are important in C. jejuni's host colonization $[4,5]$. However, little is known about genetic factors that might be important for C. jejuni's adaptation to multiple hosts, which is important since the broad host range of $C$. jejuni complicates on-farm control measures aimed at decreasing its transmission to humans.

An important factor in C. jejuni's host colonization is its capability to attach to- and/or invade epithelial cells in

\section{Biomed Central}

(c) 2011 Sanad et al; licensee BioMed Central Ltd. This is an Open Access article distributed under the terms of the Creative Commons Attribution License (http://creativecommons.org/licenses/by/2.0), which permits unrestricted use, distribution, and reproduction in any medium, provided the original work is properly cited. 
the host's gastrointestinal tract [6]. Yet, different strains of $C$. jejuni display varying capacities for cellular adherence and invasion, which could be attributed to the presence, absence and/or acquisition of certain genetic determinants that contribute to the pathobiology of this bacterium $[7,8]$. Although invasion and host adaptation are influenced by the interaction of multiple genetic factors, several individual components, including outermembrane proteins and secreted antigens can impact $C$. jejuni's adherence to and invasion of enterocytes $[7,9,10]$. Of particular interest is the invasion associated marker (iam) that was significantly associated with invasive Campylobacter [11]. This marker was discovered using random amplified polymorphic DNA (RAPD) analysis that identified a diagnostic DNA band $(1.6 \mathrm{~Kb})$ containing a genetic element (designated later as iam). Although specific PCR analysis showed that the iam was observed in $63 \%$ of the invasive isolates retrieved from diarrheic children, the marker was not detected in every potentially invasive isolate and occured in a low percentage of the non-invasive ones. Consequently, it was concluded that mutations/allele variations might have impacted both the detection of the marker and its role in mediating the invasion [11]. However, these assumptions were not tested further and the role of iam in C. jejuni's invasion and adaptation to hosts, whether humans or animals, has not been fully investigated. The limited data available suggest that the occurrence of the iam in C. jejuni might be both dependent on the characteristics of the human population understudy and associated sources of infection $[12,13]$. The latter is important since the majority of Campylobacter isolated from chicken carcasses, an established source for Campylobacter infections, also possessed the iam $[13,14]$, which suggests that the iam might play a role in the transmission of Campylobacter and/or its adaptation to different host(s). Since no data are available concerning the occurrence of iam in $C$. jejuni isolated from other hosts, the aforementioned conclusion regarding the iam association with multiple-host colonization needs further analysis. Consequently, it was important to investigate the occurrence of iam in $C$. jejuni from other important sources such as cattle [15-17] and test their potential for colonization of humans and chickens, respectively. If iam is associated with $C$. jejuni's potential for colonization of multiple hosts, this would facilitate understanding the interactive impact of major animal sources such as chicken and catthe in the transmission of Campylobacter. Therefore, we investigated the occurrence of the iam in C. jejuni isolated from cattle $(\mathrm{n}=1171)$ and determined the association of this element and its alleles with the pathogen's invasion potential of a human intestinal cell line and colonization of 1-day old chickens.

\section{Methods}

Isolation of Campylobacter jejuni from cattle and human samples

Fecal samples $(\mathrm{n}=1171)$ were collected from cattle at 4 geographic locations (North, Mid-West, East, South) across the U.S. To isolate C. jejuni, $1 \mathrm{~g}$ of each fecal sample was enriched in Preston broth for $48 \mathrm{~h}$ at $42^{\circ} \mathrm{C}$ under microaerobic conditions $\left(5 \% \mathrm{O}_{2}, 10 \% \mathrm{CO}_{2}\right.$, and $85 \% \mathrm{~N}_{2}$ ). From the enrichments that showed growth, an inoculum $(100 \mu \mathrm{l})$ was spread onto modified Cefoperazone Charcoal Deoxycholate Agar (mCCDA) plates, which were then incubated for an additional $48 \mathrm{~h}$ at $42^{\circ}$ $\mathrm{C}$ under microaerobic conditions [18]. Colonies exhibiting typical Campylobacter phenotype (flat and grey with metallic sheen) were selected from the plates and subjected to species-specific PCR analysis to confirm their identity $[19,20]$. The size of the PCR products was determined using a $1 \mathrm{~Kb}$ DNA ladder and detection was confirmed by comparison to a PCR product generated from a $C$. jejuni 81-176 (wild-type strain), which was used as a positive control in all PCR analysis. Negative controls (reactions with no DNA templates) were included in all PCR analysis to ensure specific product amplification.

Additional C. jejuni isolates from human hosts were acquired from a medical center (The Ohio State University). These isolates represented different sporadic human infections and their identity was further confirmed using the aforementioned PCR analysis.

\section{Detection of iam using RAPD typing and PCR}

To determine if the $C$. jejuni originating from cattle and human samples carried the iam locus (a diagnostic 1.6 $\mathrm{Kb}$ band), all isolates were subjected to DNA fingerprinting using RAPD analysis as described in Carvalho et al. [11]. RAPD-PCR products were then analyzed using $1.4 \%$ agarose gels, containing $0.5 \mu \mathrm{g} / \mathrm{ml}$ of ethidium bromide. RAPD fingerprints were documented and dendrograms were constructed using BioNumerics 5.1 software (Applied Maths, Inc, USA).

C. jejuni isolates that carried the iam locus as identified by the RAPD fingerprinting were tested to further confirm the presence of the iam locus. This was achieved using PCR analysis to detect a 518-bp DNA fragment inside the $1.6 \mathrm{~kb}$ band that was earlier identified as the iam locus by RAPD fingerprinting as described in Carvalho et al. [11].

\section{Detection of virulence-associated genes using PCR}

C. jejuni isolates that were identified as iam-positive using both RAPD and iam-specific PCR analysis, hereafter referred to as the iam-positive C. jejuni, were screened for genes that are important in the 
pathobiology of this pathogen. Specifically, PCR analysis was performed for the detection of the cadF (Campylobacter adherence factor), ciaB (Campylobacter invasion antigens), and $c d t \mathrm{~B}$ (cytolethal distending toxin) genes as described elsewhere [10,21,22]. Genomic DNA from C. jejuni strain 81-176 was used as a positive control, while negative controls contained the PCR reagent mix with no DNA templates.

\section{Motility assay}

To establish that iam-positive $C$. jejuni were putatively capable of host invasion and colonization, it was important to establish that the isolates were not defective in motility. For this purpose, the motility of the iam-positive C. jejuni was tested using semi-solid (0.4\%) Mueller-Hinton $(\mathrm{MH})$ agar plates as described previously [23]. The diameter of the zone of motility was measured and compared to that of C. jejuni 81-176 (positive control). The motility assays were repeated twice for each isolate, which were also tested in duplicates per each assay.

In vitro cell invasion and intracellular survival assay using human epithelial cell lines (INT-407)

The human intestinal cell invasion assays were performed using iam-negative and iam-positive $C$. jejuni isolated from both cattle and humans. For this purpose, $10^{5}$ cells $\mathrm{ml}^{-1}$ of INT-407 (human embryonic intestine, ATCC CCL 6) were seeded into each well of a 24-well tissue culture plates in Minimum Essential Medium Eagle (MEM, Fisher scientific, USA) supplemented with $10 \%$ fetal bovine serum (FBS, Fisher scientific, PA, USA). The plates were then incubated at $37^{\circ} \mathrm{C}$ in a humidified incubator with $5 \% \mathrm{CO}_{2}$ until semi-confluent mono-layers were obtained [24,25]. For infection with $C$. jejuni, the INT-407 mono-layers were washed three times and covered in MEM supplemented with 1\% FBS. Similarly, the $C$. jejuni cultures were washed three times and suspended in MEM supplemented with 1\% FBS to obtain $10^{7}$ bacteria $\mathrm{ml}^{-1}$. One $\mathrm{ml}$ of bacterial suspension was added to each well containing the INT-407 semiconfluent monolayer, achieving a 1:100 multiplicity of infection (MOI). After $3 \mathrm{~h}$ of incubation, cells were treated with gentamicin $\left(150 \mu \mathrm{g} \mathrm{ml}^{-1}\right)$ for $2 \mathrm{~h}$ to inhibit the bacteria that did not invade the cells. The infected mono-layers were washed with $1 \times$ PBS, lysed using $0.01 \%$ Triton X-100 and serially diluted (10-fold) in $1 \times$ PBS. One hundred $\mu \mathrm{l}$ of each dilution were spread on $\mathrm{MH}$ agar plates. The agar plates were then incubated for $48 \mathrm{~h}$ at $42^{\circ} \mathrm{C}$ under microaerobic conditions, after which colony forming units (CFU) were counted. Each isolate was tested in duplicate per assay, while the experiment was repeated twice on separate occasions. $C$. jejuni 81-176 and NCTC11168 were used as controls in all invasion assays. A negative control that consisted of a well containing only INT-407 with no bacteria was processed in parallel to the infected monolayers.

For the intracellular survival assays [26], Campylobacter cultures and the INT-407 cells were processed as described above. However, after treatment with gentamicin, the monolayers were covered with MEM containing $1 \%$ FBS and gentamicin $\left(10 \mu \mathrm{g} \mathrm{ml}^{-1}\right)$ and incubated for additional $24 \mathrm{~h}$ at $37^{\circ} \mathrm{C}$. Then the monolayers were washed three times with MEM containing 1\% FBS, lysed and processed as described above. The number of viable intracellular bacteria was determined by counting CFUs.

\section{Phylogenetic analysis of the iam alleles}

To determine if the iam sequences were heterogeneous and examine relationships between the iam occurring in cattle $C$. jejuni isolates and those from human samples, the 518 bp iam fragments were sequenced and subjected to a phylogenetic analysis. Briefly, iam-specific PCR products were purified using the QIAquick PCR purification kit (Qiagen, CA, USA) and commercially sequenced (Molecular and Cellular Imaging Center, OARDC, OH, USA). The identity of the sequences was confirmed by BLAST analysis. The sequences were then exported to MEGA4 software [27], aligned and analyzed. The phylogenetic tree was drawn using the Neighbor-Joining method to determine the evolutionary relationship among the sequences. The iam sequences that were analyzed in this work were deposited in GenBank under accession numbers: HM533957-HM533968, JF927289JF927291 and HQ317917.

\section{Expression analysis for the iam using quantitative real- time PCR (q-RT PCR)}

Quantitative reverse transcriptase (RT)-PCR was used to investigate an association between the expression of iam and the phenotypes of the cattle-associated C. jejuni. The q-RT PCR primers (Table 1) targeted iam conserved sequences, which were determined by multiple alignment of the iam alleles using ClustalW2 (http:// www.ebi.ac.uk/Tools/msa/clustalw2/). In order to ensure the detection of expression of different alleles, two sets of q-RT PCR primers were designed to target different fragments of the iam using Beacon Designer 7.0 software (Premier Biosoft International, Palo Alto, CA). A third set of q-RT PCR primers (Table 1) was specifically constructed to target the iam of the hyper-invasive $C$. jejuni 81-176. Total RNA was extracted (RNeasy Mini kit, Qiagen) from the iam-containing strains and two iam-negative strains, which were included as controls. Subsequently, cDNA was synthesized (SuperScript III First-Strand Synthesis SuperMix, Invitrogen) and used for q-RT PCR (SensiMixPlus SYBR RT-PCR kit, Quantance) in a Mastercycler ep realplex ${ }^{2}$ thermal cycler 
Table 1 List of primers used in this study

\begin{tabular}{|c|c|c|c|c|}
\hline Primer & Sequence $\left(5^{\prime}-3^{\prime}\right)$ & Properties & Product size & Ref. \\
\hline $\begin{array}{l}16 S \text { rRNA-F } \\
16 S \text { rRNA-R }\end{array}$ & $\begin{array}{l}\text { 5'-ATCTAATGGCTTAACCATTAAAC-3 } \\
\text { '5 '-GGACGGTAACTAGTTTAGTATT-3' }\end{array}$ & Campylobacter specific & $850 \mathrm{bp}$ & [19] \\
\hline $\begin{array}{l}\text { mapA-F } \\
\text { mapA-R }\end{array}$ & $\begin{array}{l}5 \text { '-CTATTTATTITGAGTGCTTGTG-3' } \\
5 \text { '-GCTTATTGGCCATTGTTTATTA-3' }\end{array}$ & C. jejuni specific & $589 \mathrm{bp}$ & {$[20]$} \\
\hline $\begin{array}{l}\text { cadF-F } \\
\text { cadF-R }\end{array}$ & $\begin{array}{l}5 \text { '-TTGAAGGTAATTTAGATATG-3' } \\
5 \text { '-CTAATACCTAAAGTTGAAAC-3' }\end{array}$ & cadF detection & $400 \mathrm{bp}$ & {$[10]$} \\
\hline $\begin{array}{l}c d t B-F \\
c d t B-R\end{array}$ & $\begin{array}{l}5 \text { '-GTTAAAATCCCCTGCTATCAACCA-3' } \\
5 \text { '-GTTGGCACTTGGAATTTGCAAGGC-3 ' }\end{array}$ & $c d t$ B detection & $495 \mathrm{bp}$ & [22] \\
\hline $\begin{array}{l}\text { ciaB-F } \\
\text { ciaB-R }\end{array}$ & $\begin{array}{l}5 \text { '-TTTTATCAGTCCTTA-3' } \\
5^{\prime}-\text { TTTCGGTATCATTAGC-3' }\end{array}$ & ciaB detection & $986 \mathrm{bp}$ & [21] \\
\hline Primer 1290 & $5^{\prime}$ '-GTGGATGCGA-3' & RAPD-typing & Variable & {$[11]$} \\
\hline $\begin{array}{ll}1.6-\mathrm{F} \\
1.6-\mathrm{R}\end{array}$ & $\begin{array}{c}5^{\prime} \text { '-GCGCAAAATATTATCACCC-3' } \\
5 \text { '-TTCACGACTACTATGCGG-3' }\end{array}$ & iam-specific & $518 \mathrm{bp}$ & [11] \\
\hline $\begin{array}{l}\operatorname{lam1-F} \\
\operatorname{lam} 1-\mathrm{R}\end{array}$ & $\begin{array}{c}5 \text { '-AACATTAGCGAGGAAGAT-3' } \\
5 \text { '-GTATATTCTTTAAGAGGGGTAG-3' }\end{array}$ & iam-specific (qRT-PCR) & $160 \mathrm{bp}$ & This study \\
\hline $\begin{array}{l}\operatorname{lam} 2-\mathrm{F} \\
\operatorname{lam} 2-\mathrm{R}\end{array}$ & $\begin{array}{l}5 \text { '-AACATTAGCGAGGAAGAT-3' } \\
5 \text { '-TCATTTAAACCGACCATTT-3' }\end{array}$ & iam-specific (qRT-PCR) & $160 \mathrm{bp}$ & This study \\
\hline $\begin{array}{l}\text { lam- 81176-F } \\
\text { lam- 81176-R }\end{array}$ & $\begin{array}{l}5 \text { '-AAGATAGCATACAAGAACT-3' } \\
5 \text { '-ATTCACGACTACTATAAGG-3' }\end{array}$ & iam-81176-specific (qRT-PCR) & $160 \mathrm{bp}$ & This study \\
\hline
\end{tabular}

(Eppendorf). The q-RT PCR analysis was repeated three times with two replicates in each assay and threshold cycle $\left(C_{T}\right)$ values for each sample were then averaged to represent the expression levels of the iam.

\section{Typing of iam- positive C. jejuni using pulsed field gel electrophoresis (PFGE)}

To determine the relatedness and diversity of genomic backgrounds of iam-positive C. jejuni, these isolates from cattle and human samples were analyzed using PFGE as described by Ribot et al. [28]. The resulting PFGE patterns were documented and analyzed using the BioNumerics 5.1 software (Applied Maths Inc, TX, USA). Similarity and clustering analysis of the PFGE patterns were performed using the Dice Coefficient and the unweighted pair-group method with arithmetic averages, UPGMA (optimization of $1 \%$ and position tolerance of $1.5 \%)$, respectively.

\section{In vivo chicken colonization assay}

iam-positive C. jejuni were selected for in vivo chicken colonization assays based on iam-sequence type and the iam expression profile. Subsequently, Bov-6 was selected to represent Bov-9, Bov-10, and 11 (Figure 1), while Bov-9 was excluded because it did not express the iam product. One day-old chicken (specific pathogen free) were divided into groups, each containing seven birds. Before the experimental infection, the chickens were confirmed to be Campylobacter free by testing cloacal samples collected from each individual. Groups were divided to simultaneously test iam-positive isolates versus iam-negative ones and isolates from human hosts versus those from cattle. Subsequently, $C$. jejuni isolates were suspended in $\mathrm{MH}$ broth to achieve an $\mathrm{OD}_{600}$ of 0.04 and individual chickens in each group were inoculated orally with $200 \mu \mathrm{l}$ of the suspensions $\left(\sim 2 \times 10^{5}\right.$ CFU), respectively. Seven days post-inoculation, the chickens were euthanized and the caeca were aseptically collected, weighed, and homogenized in $1 \mathrm{X}$ PBS $(\mathrm{pH}$ 7.4). The caecal extracts were serially diluted (10-fold) and $100 \mu \mathrm{l}$ from each dilution were spread onto $\mathrm{MH}$ agar plates supplemented with SR117E (Oxoid, KS, USA), a Campylobacter selective supplement. The plates were then incubated at $42^{\circ} \mathrm{C}$ under microaerobic conditions for $48 \mathrm{~h}$ and the number of CFU/g of caecal contents was calculated to determine the colonization capability of the $C$. jejuni isolates. The chickens were cared for according to the guidelines of the Association for the Assessment and Accreditation of Laboratory Animal Care (AAALAC).

\section{Statistical analysis}

Data were presented as means \pm standard error (SE) and assessed using analysis of variance (ANOVA), followed by Tukey's significance test. A $P$ value of $<0.05$ was used to indicate if differences were statistically significant.

\section{Results and discussion}

A total of 129 C. jejuni were isolated from fecal samples ( $\mathrm{n}=1171)$ collected from cattle in 4 geographic locations (North, South, Midwest, East) in the U.S. Additionally, 13 C. jejuni isolates were acquired from different sporadic human infections. The identity of the 


\section{Percent similarity (\%)}

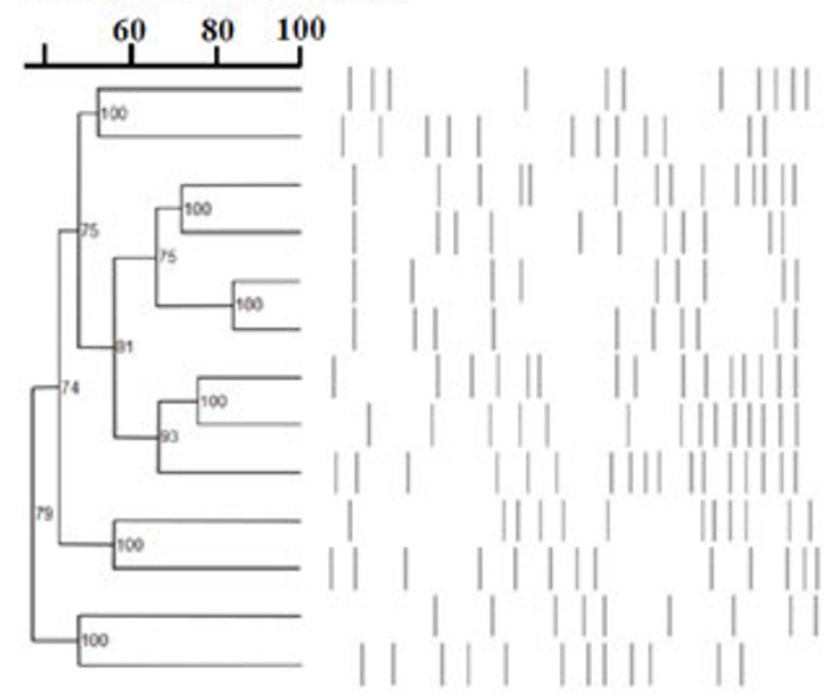

\section{Virulence genes}

\begin{tabular}{ccc} 
cadF & ciaB & cdtA \\
\hline+ & + & + \\
+ & + & + \\
+ & + & + \\
+ & + & + \\
+ & + & + \\
+ & + & + \\
+ & + & + \\
+ & + & + \\
+ & + & + \\
+ & + & + \\
+ & + & + \\
+ & + & + \\
+ & + & +
\end{tabular}

Figure 1 Dendrogram showing the pulsed-field gel electrophoresis profile for the iam-positive $\mathbf{C}$. jejuni. $\mathrm{H}-9$ and $\mathrm{H}-13$ could not be typed using PFGE. Numbers on the nodes represent the Cophenetic correlations. Virulence genes detected by PCR in iam-positive C. jejuni were included for adjacent to the corresponding PFGE profile.

C. jejuni isolates was confirmed using PCR. RAPD analysis was performed as described by Carvalho et al. [11] and showed that $10.8 \%$ of the cattle isolates possessed the $1.6 \mathrm{~Kb}$ DNA band that potentially harbors iam as compared to $54 \%$ of the human isolates. Furthermore, iam-specific PCR [11] showed that $6.8 \%$ of the cattle isolates were iam-positive as compared to $54 \%$ of the human isolates. Randomly selected isolates that did not show the $1.6 \mathrm{~Kb}$ band after RAPD analysis were also observed to be iam-negative using iam-specific PCR analysis. The discrepancy between the RAPD and the PCR results for the cattle isolates was not surprising since, as suggested by Carvalho et al. [11], the PCR primers might not necessarily detect iam mutated fragments/alleles. Additionally, mutations might spuriously give rise to a $1.6 \mathrm{~Kb}$ band that can be mistaken for the iam locus. Therefore, in order to limit iam false-positives that might be detected using either method, we selected isolates that possessed both the $1.6 \mathrm{~Kb}$ fragment and the iam-PCR product, referred to as iam-positive strains, for further analysis.

The iam-positive cattle isolates and 2 iam-positive human isolates $(\mathrm{H}-5, \mathrm{H}-7)$ were assessed for their capability to invade and survive in human intestinal cells (INT-407) [5,29]. Two iam-negative cattle isolates (Bov1, Bov-5) and 2 iam-negative human isolates ( $\mathrm{H}-1, \mathrm{H}-4)$ were used for comparison. Although all the iam-positive strains were motile on semi-solid Mueller-Hinton agar (data not shown), our results show that 5 (Bov-2, 3, 6,7 , and 10) of the iam-positive cattle isolates invaded
INT-407 with numbers higher than those of $C$. jejuni NCTC11168. Additionally, two isolates (Bov-7 and Bov10) were also more invasive as compared to the $C$. jejuni 81-176, a highly invasive strain (Figure 2A). Furthermore, 4 of the iam-positive cattle isolates (Bov-2, 3, 6, and 7) exhibited either equivalent or higher capacity for intracellular survival in INT-407 as compared to $C$. jejuni 81-176 (Figure 2B). In contrast, independent of the occurrence of the $i a m$, all tested human isolates exhibited significantly decreased capacity for invasion and intracellular survival in the INT-407 cell line as compared to C. jejuni 81-176 (Figure 2A and 2B). Consequently, the occurrence of the $i a m$ in the cattle and human isolates did not seem to confer any clear advantage in terms of invasiveness and the intracellular survival potential in the human cell line. However, since the iam was previously detected in $16 \%$ of non-invasive Campylobacter [11], Carvalho et al. [11] speculated that the non-invasive strains might carry a mutated variant of this marker and that different iam alleles might result in discrepancies in the invasion potential of disparate $C$. jejuni strains. This is plausible since allelic variations in other targets were also suggested to impact the virulence of different strains $[7,30]$.

Genomic analysis of the iam sequence deposited by Carvalho et al. [11] showed that the iam encodes an ABC transporter (Table 2). This is important since potential virulence factors, including surface structures such as transporters, are predicted to harbor much of the genetic diversity that characterize disparate $C$. jejuni 


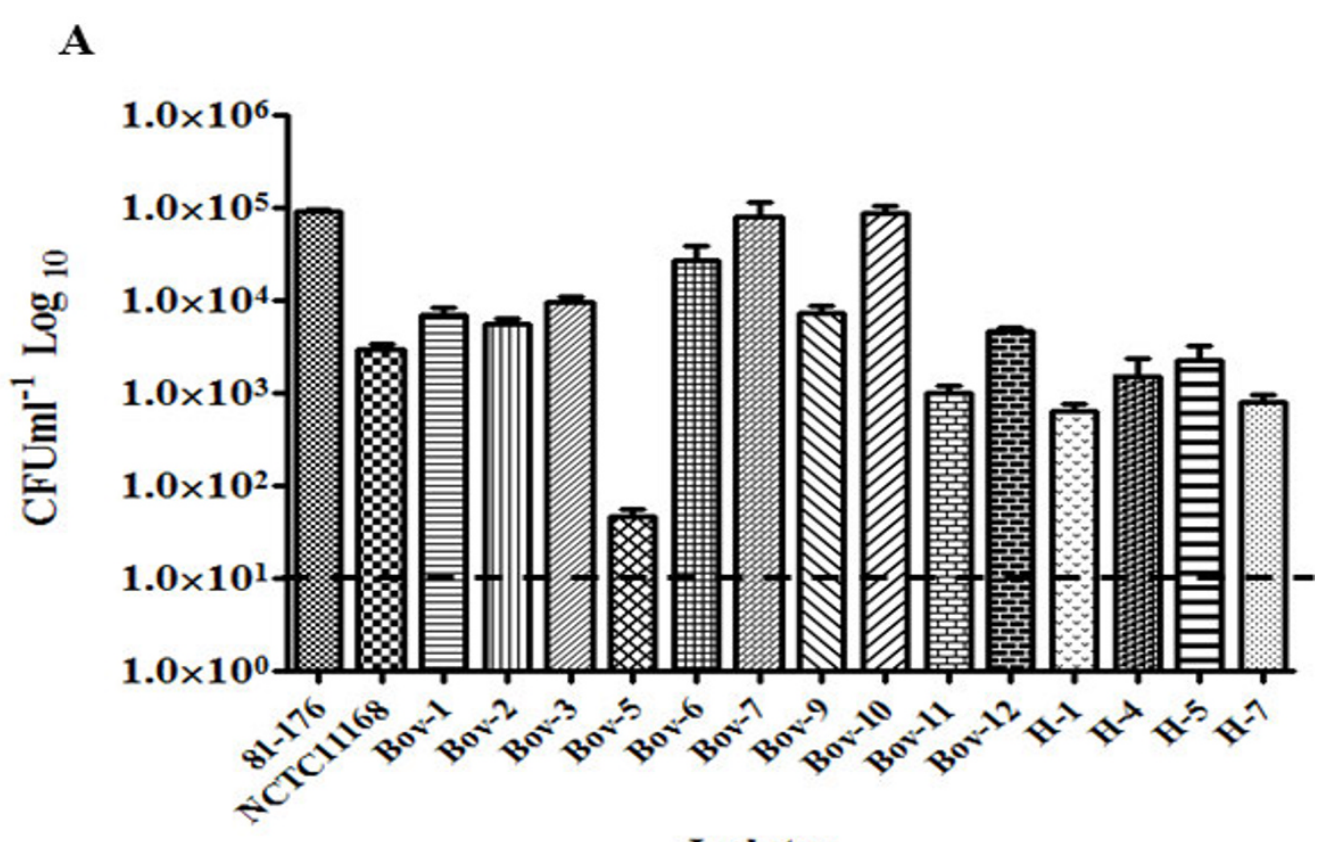

Isolates

B

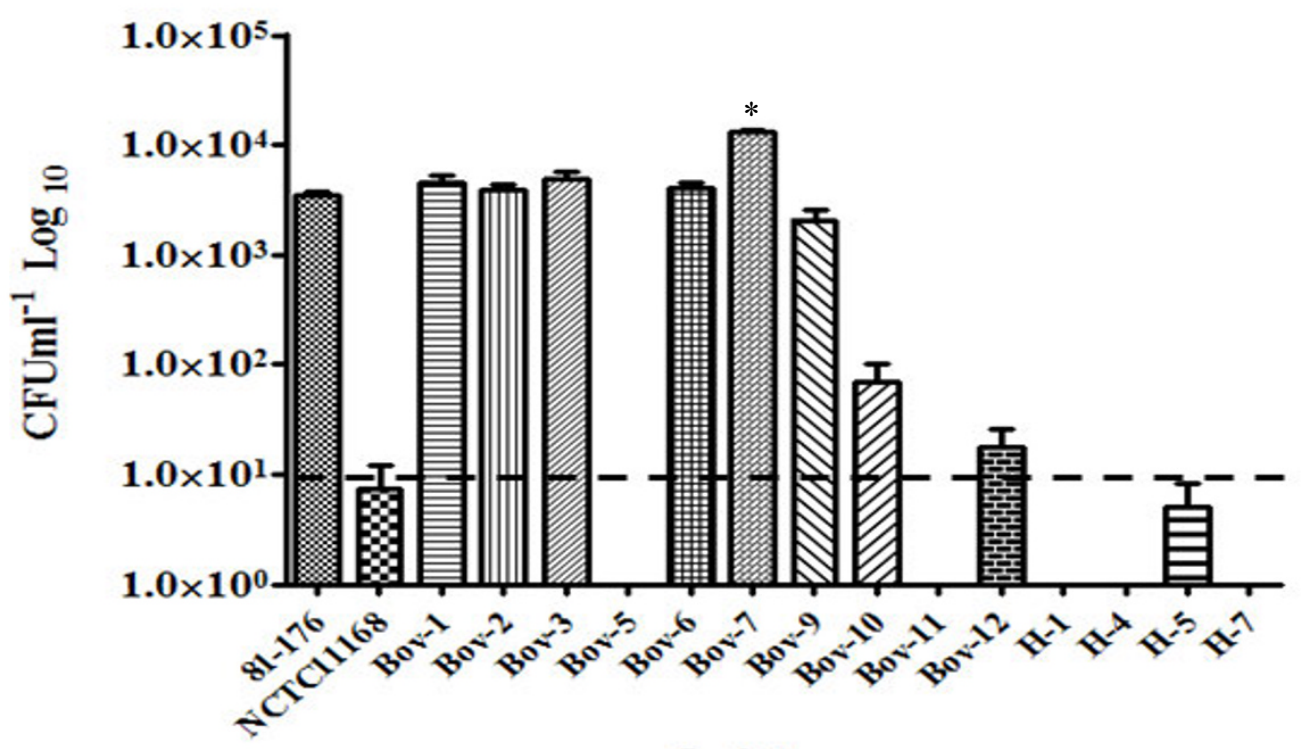

Isolates

Figure 2 Interaction of iam-containing C. jejuni with a human intestinal epithelial cells (INT-407). A. C. jejuni invasion potential of human INT-407 cells. B. Intracellular survival of C. jejuni isolates in INT-407 cells. Bov-1, Bov-5, H-1, and H-4 are iam-negative C. jejuni used for comparison with iam-containing isolates. C. jejuni 81-176 and NCTC11168 are wildtype strains used as controls. Data were log transformed and presented as mean $\pm \mathrm{SE}$ (standard error). Statistical significance was determined at $P<0.05$.

strains [3]. Interestingly, the iam was only $84 \%$ and $83 \%$ similar to sequences harbored in C. jejuni 11168 and 81-176, respectively (Table 2) and $86 \%$ similar to sequences [Genbank:HQ317917] that occurred in a newly sequenced cattle isolate; C. jejuni JL11 [31], which highlights the polymorphism of this marker. To further examine the extent of sequence polymorphism in the iam occurring in cattle $C$. jejuni isolates, we sequenced the 518 bp iam fragment. Subsequent phylogenetic analysis showed that only 4 cattle isolates (Bov-6, 10, 11, 
Table 2 Analysis of the iam marker using the BLAST algorithm.

\begin{tabular}{ccccc}
\hline & Description & Accession & $\begin{array}{c}\text { Locus Tag } \\
\text { Query } \\
\text { coverage } \\
\text { (\%) }\end{array}$ & $\begin{array}{c}\text { Similarity } \\
\text { (\%) }\end{array}$ \\
\hline $\begin{array}{ccccc}\text { C. jejuni hypothetical integral membrane protein (iamB) gene (partial cds); and ABC transporter } \\
\text { (iamA) gene (complete cds) }\end{array}$ & AF023133.1 & AF023133 & $100 \%$ & $100 \%$ \\
\hline C. jejuni subsp. jejuni IA3902 & CP001876.1 & CJSA_1559 & $100 \%$ & $84 \%$ \\
\hline C. jejuni subsp. jejuni NCTC 11168 & AL1111168.1 & Cj1647 & $100 \%$ & $84 \%$ \\
\hline C. jejuni RM1221 & CP000025.1 & CJE1819 & $100 \%$ & $84 \%$ \\
\hline C. jejuni subsp. jejuni 81116 & CP000814.1 & C8J_1549 & $100 \%$ & $83 \%$ \\
\hline C. jejuni subsp. jejuni 81-176 & CP000538.1 CJJ81176_1638 & $100 \%$ & $83 \%$ \\
\hline C. jejuni subsp. jejuni JL110034* & NA & NA & $100 \%$ & $86 \%$ \\
\hline C. jejuni subsp. doylei 269.97 & CP000768.1 JJD26997_2007 & $100 \%$ & $85 \%$ \\
\hline C. lari RM2100 & CP000932.1 & Cla_0118 & $94 \%$ & $81 \%$ \\
\hline
\end{tabular}

The sequence reported by Carvalho et al. [11] was used for query. Cds stands for coding sequence. *JL11 is a cattle isolate that was sequenced in Dr. Lin's laboratory; its sequence and complete annotations have not been submitted to Genbank, yet [31]. However, the iam homolog in JL11 was deposited in Genbank [Genbank: HQ317917]. NA: Not available

and 12) shared the same iam sequence type, while the other iam sequences from cattle and humans were heterogeneous, clustering in groups that mostly contained iam-isolates from both hosts (Figure 3A). Interestingly, the cattle isolates with identical iam sequences (Bov-6, 10, 11 and 12), did not exhibit similar invasion and intracellular survival properties in INT-407 cells (Figure $2 \mathrm{~A}$ and $2 \mathrm{~B}$ ), which suggested that there were no clear associations between an iam sequence type and the aforementioned phenotypes. Furthermore, the iam also did not appear to affect the invasion and intracellular survival potential in the tested human strains, as both iam-positive and iam-negative isolates showed similar properties, respectively.

It is possible that the presence of iam gene sequences might not be necessarily associated with the expression of its products, which might explain the lack of an apparent relationship between iam and invasiveness. Therefore, the expression of the iam was assayed for the cattle isolates using q-RT PCR, which showed that the expression levels of the iam varied between the strains (Figure 3B). Bov-3 and Bov-6 with low iam expression levels and Bov-9 with no detectable expression were still capable of invading and surviving in INT-407 cells (Figure 2A and 2B). Although isolates (Bov-7 and Bov-10) with iam expression similar to that of C. jejuni 81-176 exhibited high invasion and intracellular survival potential, isolates with relatively the highest iam expression (Bov-11 and 12) did not possess the highest capacities for the aforementioned phenotypes. Since iam expression properties in the tested isolates were consistent using two sets of qRT PCR primers (data not shown), it was concluded that the expression of iam did not seem to confer any clear advantage in terms of invasion and intracellular survival.
The virulence traits of $C$. jejuni might likely be affected by the interaction of several genetic elements $[9,10,30]$. Hence, the role of the iam in the pathobiology of $C$. jejuni, if any, would likely depend on other factors (e.g. flagella, adhesins), which in turn might need to occur in specific allelic sequences to mediate their impact. It was interesting to note that the pulsed field gel electrophoresis analysis showed that the genotypes of the iam-positive strains were mostly diverse (Figure 1 ). This indicated that the iam is occurring in diverse genotypic backgrounds that, along with the iam sequence heterogeneity, might impact the role of this locus in the pathobiology of C. jejuni. Subsequently, it was important to investigate whether the iam-containing isolates harbored genes that are commonly associated with $C$. jejuni adherence and virulence in order to ensure that our observations can be attributed to iam and not other genetic defects. Subsequently, PCR analysis showed that the iam-containing isolates carried the $c a d \mathrm{~F}, c i a \mathrm{~B}$, and $c d t \mathrm{~A}$ genes (Figure 1) that are important for $C$. jejuni pathogenesis $[9,10,12]$. Since many of the tested isolates were not defective in invasion of INT-407 cells, PCR detection of the aforementioned virulence genes was satisfactory to further confirm that the iamcontaining isolates did not appear to be deficient in genes that might be important for attachment and invasion of INT-407 cells.

We examined if there was a potential impact for the iam in C. jejuni's colonization of chickens. Out of 5 iam-containing cattle isolates tested, only one (Bov-2) colonized the chickens with numbers that were significantly higher than those of the iam-negative strains (Figure 4). Bov-7 that exhibited relatively high expression of the iam was not detected in the chickens (Figure 4). Selected human isolates colonized the chickens in similar numbers, regardless of the presence or absence 


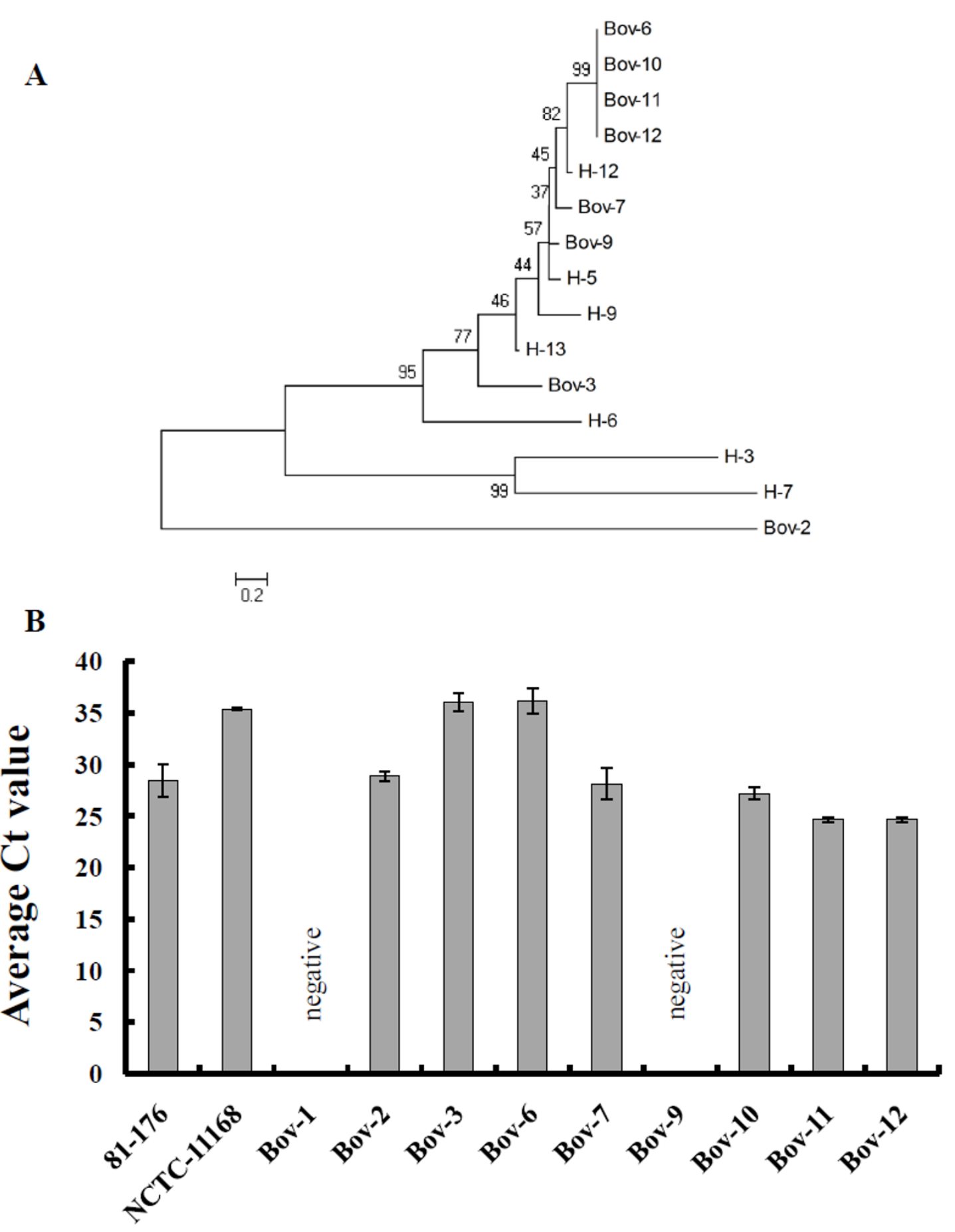

Figure 3 The evolutionary relationship between iam sequences and the expression profiles of the iam locus in cattle- and human isolates. A. The evolutionary relationship between iam sequences detected in C. jejuni isolated from human and cattle samples. The tree was drawn to scale using the Neighbor-Joining method. The percentage of replicate trees in which the iam sequences clustered together in the bootstrap test (10000 replicates) is shown next to the branches. The evolutionary distances are in the units of the number of base substitutions per site. B. Expression of iam as determined using qRT-PCR analysis. Bov-1 is an iam-negative strain. Wildtype strains (C. jejuni 81-176 and NCTC11168) that harbor the iam were also included for comparison with iam-containing cattle isolates. The data represented was collected using the primer set iam1; however, set iam2 resulted in similar results (data not shown). Expression in iam-negative strains was not detectable even after 35 cycles of amplification. 


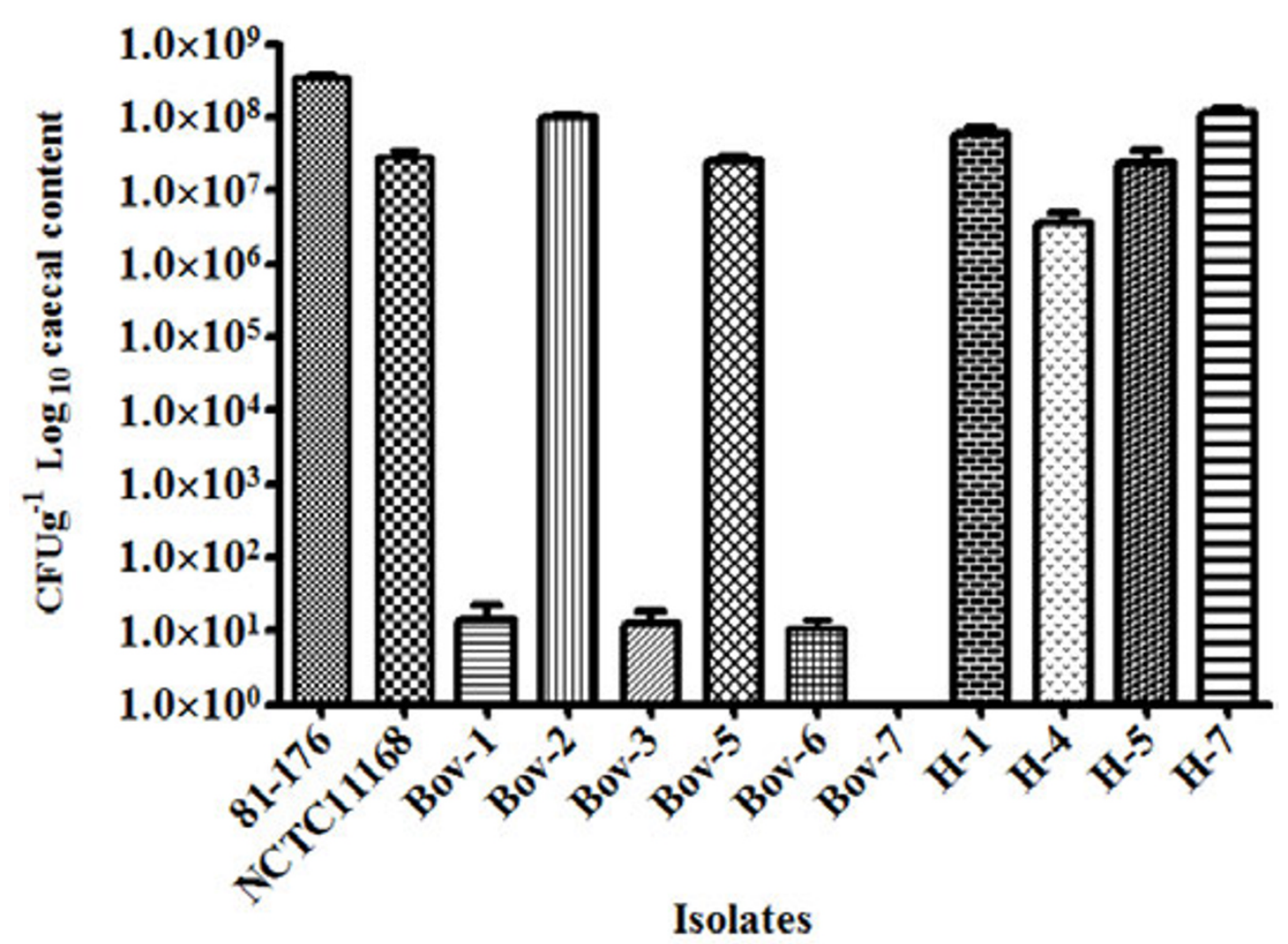

Figure 4 Chicken colonization with C. jejuni isolated from cattle and human hosts. Results were represented as means of CFU $\mathrm{g}^{-1}$ of caecum retrieved from at least six chicks per isolate tested. Bov-1, Bov-5, $\mathrm{H}-1$, and $\mathrm{H}-4$ are iam-negative $\mathrm{C}$. jejuni used for comparison with iamcontaining isolates. C. jejuni 81-176 and NCTC11168 were used as controls. Data were log transformed and presented as mean \pm SE (standard error).

of iam. Therefore, the occurrence and expression of iam apparently did not contribute to the chicken colonization potential of C. jejuni.

\section{Conclusions}

Carvalho et al. [11] only correlated the occurrence of the iam in a certain number of invasive $C$. jejuni using typing techniques, while acknowledging the existence of the marker in a relatively smaller percentage of non-invasive strains. Our analysis was more rigorous and included attempts to associate the iam with several important phenotypes. We report that the iam does not necessarily contribute to invasion and survival in human intestinal cells or colonization of chickens. Subsequently, the use of the iam as a virulence determinant in epidemiological studies (e.g. references 11-14) might be potentially misleading and might require reevaluation. However, it must be noted that despite our extensive sampling efforts, only a limited number of iam-containing C. jejuni were isolated in this study. This small number of isolates tested in this study necessitates a cautious interpretation of the data regarding the contribution of iam to invasive properties of $C$. jejuni. This can be clarified using alternative approaches such as testing deletion mutants of this marker in future experiments.

\section{Acknowledgements}

Research in Dr. Rajashekara's laboratory is supported by the Ohio Agricultural Research and Development Center (OARDC), The Ohio State University, and the USDA grant 2007-03109. Yasser M. Sanad is supported by a PhD scholarship from the Egyptian Ministry of Higher Education.

\section{Author details}

'Food Animal Health Research Program, Ohio Agricultural Research and Development Center, Department of Veterinary Preventive Medicine, The Ohio State University, Wooster, OH 44691, USA. ${ }^{2}$ Department of Animal Science, The University of Tennessee, Knoxville, TN 37996, USA.

\section{Authors' contributions}

Conceived and designed the experiments: IIK YMS GR. Performed and analyzed the experiments: YMS IIK ZL GR. Wrote the paper: IIK, YMS, GR. Reviewed, edited and approved manuscript: IIK YMS GR JL JTL. All the authors read and approved the manuscript.

\section{Competing interests}

The authors declare that they have no competing interests.

Received: 19 November 2011 Accepted: 30 December 2011 Published: 30 December 2011 


\section{References}

1. Vandamme P, De Ley J: Proposal for a New Family, Campylobacteraceae. Int J Syst Bacteriol 1991, 41:451-455.

2. Allos BM: Campylobacter jejuni infections: update on emerging issues and trends. Clin Infect Dis 2001, 32:1201-1206.

3. McCarthy ND, Colles FM, Dingle KE, Bagnall MC, Manning G, Maiden MC, Falush D: Host-associated genetic import in Campylobacter jejuni. Emerg Infect Dis 2007, 13:267-272.

4. Konkel ME, Monteville MR, Rivera-Amill V, Joens LA: The pathogenesis of Campylobacter jejuni-mediated enteritis. Curr Issues Intest Microbiol 2001, 2:55-71.

5. Hendrixson DR, DiRita VJ: Identification of Campylobacter jejuni genes involved in commensal colonization of the chick gastrointestinal tract. Mol Microbiol 2004, 52:471-484

6. Ketley JM: Pathogenesis of enteric infection by Campylobacter. Microbiology 1997, 143:5-21.

7. Fearnley C, Manning G, Bagnall M, Javed MA, Wassenaar TM, Newell DG: Identification of hyperinvasive Campylobacter jejuni strains isolated from poultry and human clinical sources. J Med Microbiol 2008, 57:570-580.

8. Hofreuter D, Novik V, Galán JE: Metabolic diversity in Campylobacter jejuni enhances specific tissue colonization. Cell Host Microbe 2008, 4:425-433.

9. Konkel ME, Garvis SG, Tipton SL, Anderson DE Jr, Cieplak W Jr: Identification and molecular cloning of a gene encoding a fibronectinbinding protein (CadF) from Campylobacter jejuni. Mol Microbiol 1997, 24:953-963.

10. Konkel ME, Gray SA, Kim BJ, Garvis SG, Yoon J: Identification of the enteropathogens Campylobacter jejuni and Campylobacter coli based on the cadF virulence gene and its product. J Clin Microbiol 1999, 37:510-517.

11. Carvalho AC, Ruiz-Palacios GM, Ramos-Cervantes $P$, Cervantes LE, Jiang $X$, Pickering LK: Molecular characterization of invasive and noninvasive Campylobacter jejuni and Campylobacter coli isolates. J Clin Microbiol 2001, 39:1353-1359.

12. Al-Mahmeed A, Senok AC, Ismaeel AY, Bindayna KM, Tabbara KS, Botta GA: Clinical relevance of virulence genes in Campylobacter jejuni isolates in Bahrain. J Appl Microbiol 2006, 55:839-843.

13. Rozynek E, Dzierzanowska-Fangrat K, Jozwiak P, Popowski J, Korsak D, Dzierzanowska D: Prevalence of potential virulence markers in Polish Campylobacter jejuni and Campylobacter coli isolates obtained from hospitalized children and from chicken carcasses. J Med Microbiol 2005, 54:615-619.

14. Korsak D, Dzierzanowska-Fangrat K, Popowskip J, Rozynek E: Incidence of the virulence markers iam in Campylobacter jejuni and Campylobacter coli strains isolated from poultry carcases. Rocz Panstw Zakl Hig 2004, 55:307-312.

15. de Haan CP, Kivistö RI, Hakkinen M, Corander J, Hänninen ML: Multilocus sequence types of Finnish bovine Campylobacter jejuni isolates and their attribution to human infections. BMC Microbiol 2010, 10:200.

16. Grove-White DH, Leatherbarrow AJ, Cripps PJ, Diggle PJ, French NP. Molecular epidemiology and genetic diversity of Campylobacter jejuni in ruminants. Epidemiol Infect 2010, 7:1-11.

17. Wilson DJ, Gabriel E, Leatherbarrow AJ, Cheesbrough J, Gee S, Bolton E, Fox A, Fearnhead P, Hart CA, Diggle PJ: Tracing the source of campylobacteriosis. PLoS Genet 2008, 4:e1000203.

18. Engberg J, On SLW, Harrington CS, Gerner-Smidt P: Prevalence of Campylobacter, Arcobacter, Helicobacter, and Sutterella spp. in Human Fecal Samples as Estimated by a Reevaluation of Isolation Methods for Campylobacters. J Clin Microbiol 2000, 38:286-291.

19. Linton D, Lawson AJ, Owen RJ, Stanley J: PCR detection, identification to species level and fingerprinting of Campylobacter jejuni and Campylobacter coli direct from diarrheic samples. J Clin Microbiol 1997 35:2568-2572.

20. Denis M, Soumet C, Rivoal K, Ermel G, Blivet D, Salvat G, Colin P: Development of a m-PCR assay for simultaneous identification of Campylobacter jejuni and C. coli. Lett Appl Microbiol 1999, 29:406-410.

21. Datta S, Niwa H, Itoh K: Prevalence of 11 pathogenic genes of Campylobacter jejuni by PCR in strains from humans, poultry meat and broiler and bovine faeces. J Med Microbiol 2003, 52:345-348,

22. Bang DD, Scheutz F, Gradel KO, Nielsen EM, Pedersen K, Engberg J, GernerSmidt $P$, Handberg K, Madsen M: Detection of seven virulence and toxin genes of Campylobacter jejuni and Campylobacter coli isolates from different sources and cytolethal distending toxin production suggest potential diversity of pathogenic properties among isolates. Genome Lett 2003, 2:62-72.

23. Fields JA, Thompson SA: Campylobacter jejuni CsrA mediates oxidative stress responses, biofilm formation, and host cell invasion. J Bacteriol 2008, 190:3411-3416.

24. Monteville MR, Yoon JE, Konkel ME: Maximal adherence and invasion of INT 407 cells by Campylobacter jejuni requires the CadF outermembrane protein and microfilament reorganization. Microbiology 2003 149:153-165.

25. Konkel ME, Kim BJ, Rivera-Amill V, Garvis SG: Bacterial secreted proteins are required for the internalisation of Campylobacter jejuni into cultured mammalian cells. Mol Microbiol 1999, 32:691-701.

26. Konkel ME, Hayes SF, Joens LA, Cieplak W Jr: Characteristics of the internalization and intracellular survival of Campylobacter jejuni in human epithelial cell cultures. Microb Pathog 1992, 13:357-370.

27. Tamura K, Dudley J, Nei M, Kumar S: MEGA4: Molecular Evolutionary Genetics Analysis (MEGA) software version 4.0. Mol Biol Evol 2007, 24:1596-1599.

28. Ribot EM, Fitzgerald C, Kubota K, Swaminathan B, Barrett TJ: Rapid pulsedfield gel electrophoresis protocol for subtyping of Campylobacter jejuni. $J$ Clin Microbiol 2001, 39:1889-1894.

29. Hu L, Kopecko DJ: Campylobacter jejuni 81-176 associates with microtubules and dynein during invasion of human intestinal cells. Infect Immun 1999, 67:4171-4182.

30. Poly F, Ewing C, Goon S, Hickey TE, Rockabrand D, Majam G, Lee L, Phan J, Savarino NJ, Guerry P: Heterogeneity of a Campylobacter jejuni protein that is secreted through the flagellar filament. Infect Immun 2007, 75:3859-3867.

31. Zeng $X, X u F$, Lin J: Whole genome sequencing of a unique Campylobacter jejuni strain with functional ferric Enterobactin acquisition system [abstract B-2986]. Abstr Gen Meet Am Soc Microbiol 2010, 213.

doi:10.1186/1756-0500-4-570

Cite this article as: Sanad et al:: Occurrence of the invasion associated marker (iam) in Campylobacter jejuni isolated from cattle. BMC Research Notes 2011 4:570.

\section{Submit your next manuscript to BioMed Central and take full advantage of:}

- Convenient online submission

- Thorough peer review

- No space constraints or color figure charges

- Immediate publication on acceptance

- Inclusion in PubMed, CAS, Scopus and Google Scholar

- Research which is freely available for redistribution

Submit your manuscript at www.biomedcentral.com/submit
C Biomed Central 